\title{
eCOti
DiAno
}

Revista Mídia e Cotidiano

Artigo Seção Temática

Volume 13, Número 2, agosto de 2019

Submetido em: 17/06/2019

Aprovado em: 24/07/2019

\section{A ecosofia de Michel Maffesoli e suas implicações tecnocomunicacionais}

\section{The ecosophy of Michel Maffesoli and its implications in terms of techno- communication elements}

Dayana Melo da SILVA ${ }^{1}$

\section{Resumo}

Este artigo tem o objetivo de apresentar os argumentos sociológicos e filosóficos sobre os quais se fundamenta a noção de ecosofia desenvolvida por Michel Maffesoli. Por conseguinte, busca-se compreender as implicações tecnocomunicacionais dessa noção na época atual, que é marcada pela emergência e desenvolvimento das tecnologias digitais e em rede e pela iminência de um colapso ambiental global. Observa-se que essa perspectiva ecosófica é caracterizada pelos movimentos de valorização da comida orgânica, de defesa da fauna, da flora e do território, engendrados, em grande medida, pelas redes digitais. O paradoxo está no fato dessas tecnologias serem elementos de conexão social e de agravamento da crise ambiental.

Palavras-chave: Michel Maffesoli; Ecosofia; Comunicação; Tecnologia; Crise ambiental.

\begin{abstract}
The aim of this article is to present the sociological and philosophical arguments that underlie the notion of ecosophy developed by Michel Maffesoli. It seeks to understand this notion's implications in terms of techno-communications in the current era, marked by the emergence and development of digital networked technologies and by the imminence of a global environmental collapse. It is observed that the ecosophy is characterized by movements that promote the appreciation of organic food, the protection of the fauna, flora and the territory, largely generated by digital networks. The paradox lies in the fact that these technologies create elements of social connection whilst, at the same time, they worsen the environmental crisis.
\end{abstract}

Keywords: Michel Maffesoli; Ecosophy; Communication; Technology; Environmental crisis.

\footnotetext{
${ }^{1}$ Pesquisadora de pós-doutorado na Escola de Comunicações e Artes da Universidade de São Paulo (ECAUSP). Doutora em Sociologia pela Université Sorbonne Paris Cité - Paris V. E-mail: dayanamelo@ usp.br.
} 


\section{Introdução}

Reciclar o lixo, andar de bicicleta, utilizar transporte público, diminuir o consumo de carne, comer alimentos orgânicos, entre outras práticas, caracterizam uma relação humana mais harmoniosa com o meio ambiente. Do mesmo modo, os movimentos de defesa da fauna, da flora e do território urbano e rural compõem o atual cenário social e ambiental. Essas práticas e movimentos atravessam a vida cotidiana e são, em grande medida, engendradas pelas tecnologias digitais e em rede, que possibilitam o surgimento de um novo espírito comunitário, plural e complexo.

Isso porque, no âmbito específico dessas comunidades e experiências comunitárias, as tecnologias, empregadas durante a modernidade em um sentido racionalista, mobilizam na pós-modernidade emoções e comunhões. Desse paradoxo epocal, surge um outro paradoxo, qual seja, o fato de essas tecnologias continuarem e mesmo aprofundarem o processo de devastação do mundo natural iniciado pelos modernos. Eis um dos aspectos centrais da concepção de ecosofia desenvolvida por Michel Maffesoli (2010, 2017b), também caracterizada pela interação, reversibilidade e reconexão com o outro, seja este o outro da natureza (cosmos), da tribo (microcosmo) ou do sagrado (macrocosmo) (MAFFESOLI, 2014, p. 208).

Antes de ser empregada por Maffesoli, a palavra ecosofia, ou sabedoria do habitat, da casa comum, aparece de maneira distinta na obra de Arne Næss (1998) e Félix Guattari (2008, 2013), tendo a sua origem filosófica no pensamento de Charles Fourier (SCHÉRER, 2001). Ela também consiste em um desdobramento ou mesmo em uma reformulação do pensamento ecológico que, entre as décadas de 1960 e 1970, emergiu no mundo ocidental na forma dos movimentos ecologistas e de uma perspectiva humanista baseada no valor e na obrigação (GOODPASTER, 1978).

Todavia, de acordo com Maffesoli, essa lógica ecologista de proteção da natureza segue o mesmo caminho da lógica moderna de exploração da natureza, no sentido de pensá-la como algo separado da cultura e exterior à condição humana. É nesse sentido que Maffesoli desenvolve a sua ecosofia, pensando-a de forma holística e, ao mesmo tempo, relacional, e integrando-a às práticas cotidianas, ao território e a outras 


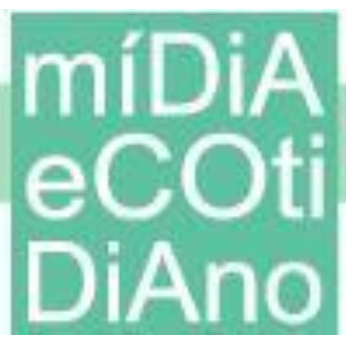

formas espaciais, inclusive àquelas produzidas pelas tecnologias digitais e em rede. Isso indica que, como prática, a ecosofia maffesoliana sugere um novo olhar para os fenômenos que integram sociedade, tecnologia e ambiente, indicando, assim, os fundamentos de uma sabedoria do habitat que deve incluir os modos de existência tecnológicos.

Com objetivo de investigar a interpretação maffesoliana de ecosofia, destacamos que este artigo está dividido em três eixos de compreensão. Em um primeiro momento, apresentaremos uma leitura acerca das origens e desenvolvimento do pensamento ecosófico, tomando-se por base as obras de Fourier, Næss e Guattari. Em seguida, abordaremos os argumentos sociológicos e filosóficos sobre os quais se fundamenta a noção de ecosofia desenvolvida por Maffesoli, bem como o diálogo entre essa concepção e as concepções precedentes, seus pontos de contato e divergência. Por fim, investigaremos as implicações tecnocomunicacionais da noção maffesoliana de ecosofia na época atual, que é marcada pela emergência e desenvolvimento das tecnologias digitais e em rede e pela iminência de um colapso ambiental global.

\section{Origem e desenvolvimento do pensamento ecosófico: nos rastros de Charles Fourier,}

\section{Arne Næss e Félix Guattari}

Em seu sentido originário, a noção de ecosofia, forjada pelo filósofo norueguês Arne Næss na década de 1970, indica uma mudança no pensamento e na prática ecológica, que sai do antropocentrismo e vai em direção ao biocentrismo. Essa noção está ligada a uma outra noção igualmente criada por Næss e nomeada ecologia profunda (deep ecology), que também inverte a perspectiva antropocêntrica. De fato, essa nova concepção de filosofia ecológica busca retirar o homem do centro das discussões e colocar em seu lugar todos os seres vivos. Ela também busca ir além da visão utilitarista das coisas a fim de compreender seus valores intrínsecos, isto é, o conjunto de seres vivos que constituem a biosfera, bem como o lugar da humanidade nesse todo ecosférico.

A palavra ecosofia é etimologicamente constituída com base na combinação das palavras gregas oikos (casa, bem doméstico, habitat, ambiente natural) e sophia (conhecimento, sabedoria). O prefixo eco, encontrado nas palavras ecologia e economia, se liga ao sufixo sofia, encontrado na palavra filosofia, para se opor à ideia de logos e 


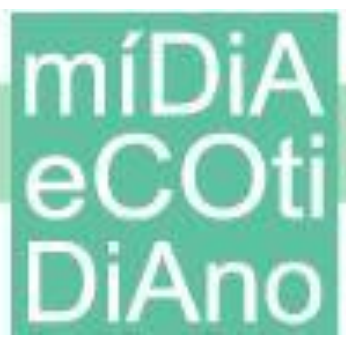

constituir uma sabedoria do habitar. Næss descreve a noção de ecosofia da seguinte forma: "uma ecosofia torna-se uma visão filosófica do mundo ou um sistema inspirado pelas condições da vida na ecosfera. Ela deve ser capaz de servir como uma fundamentação filosófica do indivíduo para uma aceitação dos princípios ou plataforma da ecologia profunda" (NÆSS, 1998, p. 37-38, tradução nossa).

Posteriormente, nos estudos de Félix Guattari (2008), a noção de ecosofia é articulada com base em uma perspectiva ética, política e estética, constituindo-se como um campo de práticas fundamentadas na necessidade de ir além dos paradigmas dos movimentos revolucionários do século XX e substituir as antigas formas de engajamento com o intuito de construir um quadro problemático mais complexo e transversal. O que indica pensar as inter-relações entre vida social, produção de subjetividades humanas e meio ambiente. No desenvolvimento da sua argumentação teórica, Guattari parte das transformações técnico-científicas vivenciadas pela Terra, que geraram fenômenos ambientais que ameaçam as formas de vida aqui existentes, e também da exploração contínua do planeta pelo homem e do aumento do crescimento demográfico. Com isso, ele propõe uma concepção de ecosofia que consiste em uma recomposição de práticas sociais e individuais, uma nova relação da humanidade com o socius, a psique e a natureza, atualmente degradada, mas com a qual devemos continuar a fazer-com, tomando-se por base a reorganização dos objetivos e métodos disso que esse psicanalista e filósofo francês define como "o conjunto do movimento social." (GUATTARI, 2008, p. 33).

Guattari constrói sua perspectiva ecosófica baseada em três eixos: ecosofia social, ecosofia mental e ecosofia ambiental. A ecosofia social é fundamentada em uma nova relação com as realidades econômicas e sociais, tanto no domínio microssocial quanto institucional; a ecosofia mental está ligada às subjetividades humanas e aos vetores de subjetivação, isto é, aos processos de produção e agenciamento de subjetividades em contextos individuais e coletivos; a ecologia ambiental é definida por uma nova relação com a natureza e com tudo o que constitui o ambiente natural. Enquanto prática, a ecosofia visa construir novas conexões, novos modos de agenciamento e produção de subjetividades, novas narrativas enunciativas, novas intensidades, enfim, novas formas de agrupamento que vão do "ser" ao "ser-em-grupo" e que são 


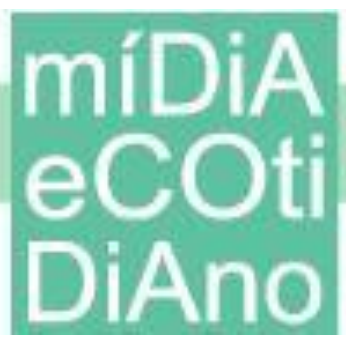

caracterizadas por uma nova relação com os humanos, coisas e ambientes, sendo capaz de modificar o ambiente social e material para impulsionar as mentalidades em direção ao conhecimento, à cultura, às sociabilidades e às sensibilidades.

De acordo com Guattari, por meio dessas novas experiências, práticas antigas se misturaram sem necessariamente perder seus elos constitutivos. Em relação aos movimentos ecologistas tradicionais, o filósofo acredita que esses movimentos, além de mascarar um conjunto de subjetividades, também mascaram a potencialidade dos poderes econômicos e financeiros e a complexidade da relação entre os seres humanos e seu ambiente natural e social. A ecosofia é, portanto, pensada com base em uma abertura, um processo de heterogênese, transversal, uma nova relação com o eu e com o outro.

Em Qu'est-ce que l'écosophie? (O que é a ecosofia?), livro que reúne textos inéditos escritos por Guattari entre os anos de 1985 e 1992, observamos a continuação dessa nova teoria ecológica global que se fundamenta não apenas nas relações ambientais, mas também sociais e subjetivas. De fato, é necessário destacar a atenção dada por Guattari às mudanças e transformações políticas, econômicas e sociais e à impotência dos movimentos tradicionais diante de um contexto que ele chama de Capitalismo Mundial Integrado. Como resultado, as questões ambientais estão diretamente relacionadas às questões científicas, econômicas, políticas, sociais, urbanas e mentais que, por sua vez, possuem dimensões materiais e subjetivas.

Nesse sentido, observamos em Guattari a ideia de uma ecosofia na qual busca-se articular a noção de "objeto ecosófico", que seria, segundo ele, mais fértil do que a de "objeto ecossistêmico". O objeto ecosófico como sistema de modelagem foi articulado com base nas dimensões de fluxo, máquina, valor e território existencial, no qual não há distinção entre um "objeto concreto" e um "sistema de descrição". Uma percepção que nos ajuda a entender como fenômenos ambientais, sociais, econômicos, políticos, midiáticos, tecnológicos, subjetivos e mentais, entre outros, estão relacionados, como esses fenômenos influenciam uns aos outros e quais são as suas implicações em uma escala planetária.

Para Guattari, a humanidade e a biosfera estão ligadas e o futuro de ambas depende disso que as envolve, ou seja, da mecanosfera. Guattari indica, ainda, a necessidade de uma reinvenção nas práticas humanas, bem como o surgimento de um 
nomadismo selvagem, territorializado, próximo ao dos povos indígenas da América précolombiana ou dos aborígines da Austrália. O que indica a emergência de novas e múltiplas conexões com o mundo. Guattari também acredita que a ecosofia pode até mesmo mudar as práticas arquitetônicas e urbanas das cidades. Em resumo, o filósofo afirma que:

(...) a qualidade da produção dessa nova subjetividade se torna o objetivo principal das atividades humanas. Portanto, tecnologias apropriadas devem ser colocadas ao seu serviço. Tal reorientação não é apenas uma questão de especialistas, mas requer uma mobilização de todos os componentes da "cidade subjetiva" (GUATTARI, 2013, p. 51, tradução nossa).

A filósofa Isabelle Stengers e o historiador Philippe Pignarre compreendem a tentativa guattariana de criar um conceito de ecosofia como um "pensamento pelo ambiente", devendo esse pensamento direcionar a sua atenção para a devastação desses ambientes, ou meios. Com isso, Stengers e Pignarre tecem as ligações entre a devastação dos ambientes natural e social e as práticas capitalistas. A noção de comércio, uma arte antiga ligada à arte da negociação e que está além do simples consumo ou das relações entre os seres humanos, foi, de acordo com os autores, completamente esvaziada pelo capitalismo.

Em muitas tradições, cuidar é saber negociar com poderes invisíveis, é comercializar com eles. É aprender o que esses poderes, que se tornaram inimigos, querem em reparo. Os curandeiros que sabem negociar com o invisível não são "pessoas de fé", nem crentes ingênuos. É necessário ter participado de uma "negociata", em um país onde essa arte ainda é cultivada, para compreender como a mesma palavra pode indissociavelmente designar a troca de bens, mas também a troca de ideias, o "comércio dos espíritos", como se dizia (STENGERS; PIGNARRE, 2005, p. 158, tradução nossa).

Fundamentados na definição do pensamento e prática ecosófica, Stengers e Pignarre dissertam sobre a ideia de comércio em um sentido amplo e substancial. Os autores encontram na imagem de Hermes - deus grego dos comerciantes, escritores, ladrões, da astúcia e das trocas - um exemplo dessa relação complexa que estava baseada 


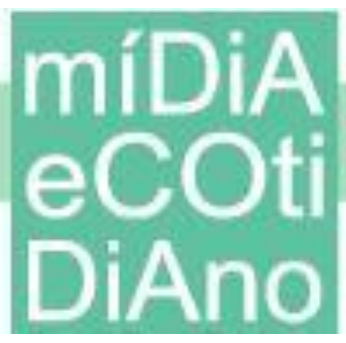

na desconfiança no outro, mas também na confiança em si. Da mesma forma, os autores destacam outras mudanças nas relações com os ambientes natural e social em virtude das práticas capitalistas nascentes, como a apropriação de espaços comuns, a definiç̧ão do direito à propriedade e o nascimento da força de trabalho, fenômenos que estão interrelacionados e ligados ao processo de exploração da natureza pelo homem e do homem pelo homem.

De fato, observamos na abordagem ecosófica de Guattari uma contribuição mais centrada no homem, diferentemente da proposta de Næss. Todavia, ambas se opõem ao pensamento cartesiano, que coloca o homem como "mestre e senhor da natureza", e que influenciou a própria concepção de dominação do mundo natural, base do pensamento moderno. Daí a ideia do ser humano considerado como sujeito pensante e racional, e a natureza como um objeto sujeito ao domínio da razão.

René Schérer (2001), por sua vez, vê em um pensamento anterior, o de Charles Fourier, considerado uma das principais figuras do socialismo crítico utópico, os primeiros traços de uma ecosofia. Os dois manuscritos de Fourier apresentados e analisados por Schérer são o Détérioration matérielle de la planète (Deterioração material do planeta, publicado em 1847) e Médecine naturelle ou attrayante composée (Medicina Natural ou atraente composta, publicado em 1848) e que inclui o texto Gastrosophie (Gastrosofia), posteriormente anexado ao Nouveau monde amoureux (Novo mundo apaixonado). Neles, observa-se a inquietação diante da deterioração do planeta como sintoma do modo de vida do homem moderno e da sua ideia de progresso, que aparece de maneira evidente.

Com base em uma teoria cósmica e em uma filosofia da natureza e do ambiente, já fundamentada na inter-relação entre natureza, sociedade e espírito, Fourier buscou reconstruir os laços rompidos entre a humanidade e o seu meio. De acordo com Schérer:

Se a ecosofia de Guattari permite nomear, unificar, fornecer um "plano de consistência" para unidade dos movimentos, ela recebe em retorno da grande obra de Fourier uma potência, um alívio inegável; uma capacidade de extensão e extrapolação no âmbito puramente especulativo e estético (SCHÉRER, 2001, p. 20-21, tradução nossa). 


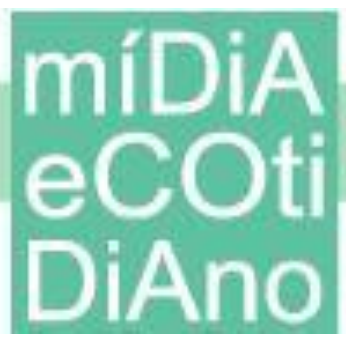

Pensar a ecosofia com Fourier significa, assim, pensar os laços entre os meios natural, social e mental tomando-se por base uma filosofia que coloca em relação sujeito e objeto, o mundo dito primitivo e o mundo dito civilizado, o orgânico e o inorgânico, o material e o imaterial, o pequeno e o cósmico, a realidade social e humana e os sonhos utópicos. Quando o filósofo fala da "Deterioração material do planeta", título de um dos manuscritos estudados por Schérer, ele já indica esses laços intrínsecos, essa multiplicidade de fluxos, as singularidades e as generalidades entre a atividade humana, a ordem social e o todo universal.

Para Patrick Tacussel, na obra de Fourier, "A arte de associar é o objetivo concreto do imenso campo teórico cujos benefícios são elogiados de uma publicação para outra com um entusiasmo pedagógico." (TACUSSEL, 2007, p. 9, tradução nossa). Em um trabalho precedente, Tacussel afirma que para Fourier o pensamento analógico é fundado não somente nas correspondências, mas, sobretudo, em uma racionalidade expandida. (TACUSSEL, 2000). A esse respeito, deve ser enfatizado que, para Fourier, especialmente nas reflexões sobre natureza e ambiente, existe uma ligação intrínseca já esboçada entre o humano e o não-humano, e entre estes e o universo cósmico e social.

\section{A ecosofia de Michel Maffesoli: um modelo de pensamento não antropocêntrico e relacional}

Mais recentemente, a noção de ecosofia foi retomada por Michel Maffesoli (2010, 2017b), sociólogo interessado em compreender as atuais transformações que ocorrem na vida cotidiana e nas relações sociais. Para Maffesoli, são os pequenos laços, partilhas e encontros que estruturam o todo social e que engendram uma nova ambiência caracterizada pelo retorno às raízes, no sentido do retorno à Terra, ao território. Esse pensamento questiona valores e ideologias modernas, seguindo, juntamente com a abordagem sociológica compreensiva e fenomenológica, uma abordagem nietzscheana de crítica à ideologia do progresso, responsável, de acordo com Maffesoli, pelo atual colapso ambiental.

O interesse do pensamento maffesoliano está nos fenômenos e elementos que fundamentam e estruturam o vínculo social. Em suma, o interesse está no que é tecido conjuntamente e para além dos poderes oficiais (MAFFESOLI, 2008). O olhar em direção 


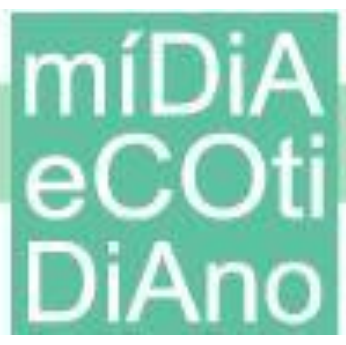

aos movimentos de retorno à Terra como método significa, assim, o olhar em direção ao reprimido, ao oculto, às brechas, àquilo que sempre esteve presente entre nós e que agora se desvela graças às mudanças climáticas, pensadas no sentido metafórico e literal da palavra clima.

Com base nessa compreensão da sociedade atual, observamos em Maffesoli a presença de um modelo de pensamento holístico, termo utilizado por Émile Durkheim para designar o aspecto geral da vida social, um processo de interação entre dois ou mais elementos que, analiticamente, tendemos a separar, a exemplo das ideias de natureza e cultura. Todavia, o holismo, na leitura maffesoliana, não indica uma teoria da totalidade, mas uma tentativa de articular essa totalidade às micropartes e aos microrganismos que a constituem, e vice-versa. Para Maffesoli, não existe um grande conjunto, mas pequenos agrupamentos conectados e mutuamente engendrados constituindo o vínculo social. Com isso, o sociólogo se questiona acerca da visão do mundo ocidental que reduziu a complexidade das realidades a uma representação utilitária e quantitativa.

Ao contrário de Guattari, que resiste a um chamado holístico - de modo que, mesmo sendo a ecologia ambiental, social e mental essenciais para a articulação da sua ecosofia, elas não são compreendidas como o retrato de um todo, mas como responsáveis por mostrar os múltiplos vetores, reuniões e agenciamentos que constituem as micro lutas políticas contra o sistema capitalista - Maffesoli não faz oposição entre o holismo, o todo, e a multiplicidade de perspectivas, tendo como objetivo situar os seres e as coisas em movimento, em outras palavras, em relação. Nesse sentido, a sua proposta se aproxima da de Næss, ao tirar o homem do centro do processo, seguindo, ainda, os caminhos traçados por Fourier, sobretudo no que concerne ao lugar predominante que este dá ao desejo e ao seu pensamento do múltiplo.

Assim, ao retraçar a concepção de ecosofia desenvolvida por Maffesoli, observamos como com base em questões sobre a violência das instituições e do Estado moderno, da crítica às leituras e análises racionalistas e individualistas, ao mito do progresso e ao ideal de sociedade projetiva, emerge uma outra imagem tão cara à imagem da ecosofia, que é da "invaginação do sentido", apresentada em seu Pequeno tratado de ecosofia (Petit traité d'écosophie) e descrita da seguinte forma: 
Retorno à essencial natureza das coisas [...] "De natura rerum", natureza das coisas feita de interdependência e correspondência. Também de conivência, não se contentando com o "não", que eu disse odioso, mas sabendo dizer sim para uma existência que, apesar de saber da sua repleta finitude, não deixa de ser experimentada como tal, desejada como tal (MAFFESOLI, 2010, p. 11-12, tradução nossa).

Do mesmo modo, vemos nessa noção de ecosofia os sinais de um pensamento associativo, relacional, no sentido das emoções compartilhadas. A ecosofia de Maffesoli vai além do antropocentrismo partindo da observação do que está além de nós, dos nossos elos cósmicos e ctônicos. Para esse pensador da pós-modernidade, nós retornamos à natureza quando nos acomodamos à Terra e a tudo o que a constitui. Desencantamento e reencantamento do mundo. Essa reconexão com o sensível está ligada a uma correspondência com as coisas, em uma palavra, co-pertencimento, que é designada por Maffesoli em diversos escritos pelo oximoro "enraizamento dinâmico", que é a própria condição do imaginário pós-moderno (MAFFESOLI, 2014).

Esse "enraizamento dinâmico" indica, ainda, uma transformação na nossa relação com o tempo. Isso significa que, se durante a modernidade era necessário que o homem fosse além do passado a fim de projetar o futuro, na pós-modernidade observa-se a integração entre passado e presente, isto é, a busca pela tradição e ao mesmo tempo a recusa pelo imobilismo. Assim, o tempo na pós-modernidade não pode ser pensado de modo projetivo, como na modernidade, nem circular, como no mundo primitivo, mas como uma espiral, um tempo marcado pela "sinergia entre fenômenos arcaicos e o desenvolvimento tecnológico" (MAFFESOLI, 2011, p. 10, tradução nossa).

Na obra Écosophie. Une écologie pour notre temps (Ecosofia. Uma ecologia para nosso tempo) Maffesoli indica a existência de uma "natureza das coisas", ideia também presente na sua obra anterior L'ordre des choses (Ordem das coisas). Para o autor, a humanidade, com base na ideologia e mito do progresso, teve a pretensão de transformar essa natureza das coisas nos conduzindo à devastação do mundo social e natural. No entanto, Maffesoli ressalta que está em curso na atualidade uma conversão lenta e profunda de uma visão econômica, baseada em uma concepção de mundo individualista, para uma visão ecosófica, inspirada em uma sabedoria comum, isto é, uma 


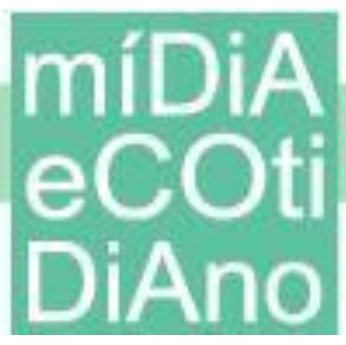

acomodação a essa natureza das coisas, também compreendida como uma sensibilidade ecosófica (MAFFESOLI, 2014, 2017b).

Decerto, o olhar em direção a essas pequenas brechas ou "resíduos", para retomar uma expressão do sociólogo italiano Vilfredo Pareto tão cara a Maffesoli, não indica uma atitude de otimismo nem de negação da devastação do mundo, mas de compreensão desse espírito do tempo pós-moderno, que é caracterizado, entre outros fatores, por uma complexidade contraditória. Nas palavras de Maffesoli "A finitude é trágica e se exprime na crueldade, mas pode haver uma forma de jubilação na aceitação dessas características próprias da natureza humana (...) É tal aceitação, atitude afirmativa quando ocorre, que lhe dá sua dimensão trágica", o autor acrescenta ainda que "A natureza trágica não é mais de negação do pecado, do mal, da imperfeição. Enfim, não é mais de negação de todos esses ingredientes que nos constituem, mas sim de aceitação do claro-escuro da existência. A natureza assim compreendida substitui a perfeição pela completude" (MAFFESOLI, 2017a, p. 2).

De acordo com Maffesoli, o fundamento dessa nova sensibilidade ecológica, ou ecosófica, está justamente na aceitação de elementos que são, ao mesmo tempo, harmoniosos e conflituosos. O sociólogo recorre, ainda, a Michel Foucault e à ideia de "domesticação" que caracteriza as instituições modernas, bem como àquilo que Norbert Elias chamou de "curialização" dos costumes, própria da dinâmica do Ocidente, a fim de ilustrar como o poder social, econômico e político da modernidade se empenhou em suprimir o selvagem, definido por ele como "uma expressão da potência nativa, primordial, societal" (MAFFESOLI, 2017a, p. 3).

Faz-se necessário destacar que a leitura maffesoliana acerca da devastação do planeta é anterior ao desenvolvimento do seu pensamento ecosófico, como pode ser observado na obra La connaissance ordinaire (O conhecimento comum), de 1985, na qual, de acordo com Maffesoli, a "busca por correspondências", observada por LéviStrauss na obra Tristes trópicos e para o qual essa busca "oferece ao cientista o mais novo terreno, aquele cuja exploração ainda pode fornecer-lhe ricas descobertas", pode ser pertinente para a compreensão da presente época, caracterizada pela separação entre natureza e cultura (MAFFESOLI, 2007, p. 19). Nesse sentido, a noção de estar-com deverá integrar-se também ao ambiente. 
O retorno da natureza à frente da cena social não é tranquilo, por isso é necessário compreendê-lo bem. Mas o fato de essa crueldade se integrar em um processo ritualizado torna-a talvez menos ofensiva. De qualquer forma, essa é a aposta que podemos fazer. Assim sendo, ao contrário de um mundo asséptico, rígido e mortificado, baseado no autocontrole (mecânica educacional) e no domínio do universo (exploração da natureza), vemos o surgimento de um mundo muito mais complexo, baseado na aleatoriedade (o modelo estocástico) que, de uma maneira orgânica, integra uma parcela da morte. Não se esqueça, se Dionísio "divindade arbustiva" refere-se à noção de território, ele também aponta para esta terra onde os mortos enterrados são a promessa de vida. A morte vivida dia a dia é também o retorno da natureza (MAFFESOLI, 2007, p. 141-142, tradução nossa).

Eis, pois, uma das primeiras definições disso que Maffesoli chama de “aceitação trágica", compreendida como o "presente que se sente precário e que, por isso, requer intensidade" (MAFFESOLI, 2015, p. 13, tradução nossa). Todavia, esse pensamento do trágico, da aceitação daquilo que é, encontra nas redes digitais um espaço de conexão e expressão de tribos e comunidades pós-modernas (MAFFESOLI; FISCHER, 2016). Nesse sentido, Maffesoli apresenta o paradoxo segundo o qual as tecnologias, que durante a modernidade foram empregadas em um sentido racionalista, mobilizam na pós-modernidade emoções e comunhões. Porém, um outro paradoxo está no fato de essas tecnologias continuarem e mesmo aprofundarem o processo de devastação do mundo natural iniciado pelos modernos. A compreensão desses dois paradoxos tecnológicos, fundamentados em uma leitura sociológica, filosófica e comunicacional das redes digitais e na relação destas com o meio, é essencial para a própria compreensão da noção de ecosofia desenvolvida por Maffesoli.

\section{Implicações tecnocomunicacionais da noção maffesoliana de ecosofia}

O desenvolvimento científico e tecnológico que se deu durante a modernidade, notadamente nos séculos XVIII e XIX, se baseou em uma lógica de dominação e exploração da natureza. Dentro dessa lógica, o mundo é visto como um objeto e o ambiente como um meio do qual o homem pode se apossar a fim de saciar as suas necessidades e desejos. Essa visão encontra as suas raízes modernas no pensamento 
cartesiano, cujos conceitos centrais governaram as relações entre conhecimento, ciência e tecnologia durante grande parte da era moderna, conforme evidencia Gilbert Simondon:

O exemplo de Descartes, que buscou pensar a natureza como um sistema técnico (...) é encontrado toda vez que uma nova ciência fornece modelos intelectuais e meios técnicos para abordar o mundo. A Química e a Física se desenvolveram no século XVIII e trouxeram, junto com o progresso da Biologia (...) uma audácia otimista aos tecnicistas e a confiança no progresso contínuo (SIMONDON, 2014, p. 187, tradução nossa).

O cartesianismo também influenciou as ideologias saint-simonianas e positivistas que se desenvolveram no decorrer do século XIX e continuaram a se reverberar ao longo do século XX. Isso porque, essa sinergia entre universalismo, racionalismo, dualismo, idealismo, antropocentrismo, projetivismo e pensamento técnico prometeico articulou uma estreita ligação entre as ideias e ideais não apenas de SaintSimon e Comte, mas também de pensadores como Durkheim e Marx, descritos por Maffesoli (2007, p. 45) como os "protagonistas da mesma epistemologia".

No entanto, como nos convida a pensar Maffesoli, com base em uma perspectiva nietzscheana, o ideal de progresso da modernidade se tornou exatamente aquilo que o pensamento racionalista buscou aniquilar, isto é, um mito. Em vez da redenção da humanidade e da instauração do paraíso sobre a Terra, o que vemos é a concretização de um processo de devastação do mundo. A amplitude dessa devastação e o papel ativo do homem nesse processo são sintetizados pela palavra Antropoceno, um termo que se refere à presente época da história da Terra na qual a humanidade se tornou uma grande força geológica capaz de impactar de forma global o ecossistema terrestre e alterar as modalidades termodinâmicas do planeta (CRUTZEN, 2006).

Martin Heidegger, de quem Maffesoli toma de empréstimo a ideia de "devastação do mundo", no texto "A questão da técnica" associa tal devastação ao desenvolvimento da técnica moderna, ou tecnologia. Porém, ao avançar no entendimento da concepção não instrumental da técnica desenvolvida por Heidegger, segundo a qual a técnica não é um simples meio ou fazer humano (HEIDEGGER, 2007, p. 376), Maffesoli atenta para um importante ponto de inversão ao qual se refere o filósofo, que é o de uma outra concepção de técnica baseada no retorno da potência do destino. O que pode ser 


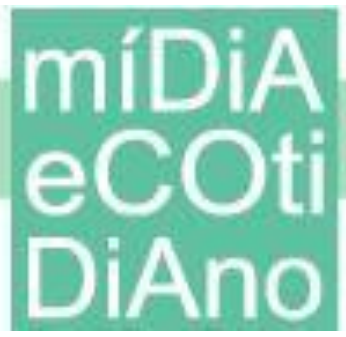

exemplificado, de acordo com o sociólogo, nas práticas juvenis, nos eventos esportivos, na histeria musical e em reuniões religiosas, onde se expressa o que o ele define como uma "selvageria da natureza" (MAFFESOLI, 2015, p. 12).

De acordo com Maffesoli, foi o "desencantamento do mundo" descrito por Weber que conduziu a modernidade à ideia destrutiva de uma natureza a ser explorada. Contudo, para o sociólogo, Heidegger rompe com essa concepção paranoica do mundo ao retomar a célebre frase do poeta Hölderlin, que diz que "Lá, onde há o perigo, cresce também aquilo que salva", a fim de desenvolver a ideia de que quanto mais nos aproximamos do perigo, mais claramente os caminhos que nos levam ao que salva começam a clarear. Nas palavras de Maffesoli (2015, p. 15, tradução nossa): "Essa é a lição que parece reter todos esses ‘tecno-mágicos' que são os usuários dos novos meios de comunicação interativos que, por sua ação, participam de um verdadeiro reencantamento do mundo".

É nesse sentido que Maffesoli associa a noção de ecosofia e os movimentos que emergem desse reeencantamento às tecnologias de informação e comunicação. Todavia, conforme observamos anteriormente, a mesma tecnologia responsável por mobilizar tribos, comunidades e agrupamentos pós-modernos, também é responsável por perpetuar a lógica de devastação do mundo natural e acelerar o iminente colapso ambiental global. Afinal, devemos sempre ter em mente o contínuo impacto dessas tecnologias nos ecossistemas aquáticos e terrestres ${ }^{2}$.

Conforme demonstra Hélène Houdayer, apesar dos sucessivos alertas emitidos pelos ambientalistas, das advertências dadas pelos especialistas, do comprometimento de intelectuais para colocar fim nessa relação de dominação da natureza pelo homem, a marca do humano em seu ambiente é ainda muito forte e devastadora. Todavia, ao apoiar-se na concepção maffesoliana de ecosofia, a socióloga também aponta para uma busca pelo ambiente que nos convida a adquirir uma "mentalidade ecológica" de "natureza utópica". Do mesmo modo, ela retoma a ideia de

\footnotetext{
${ }^{2}$ Sobre a relação intrínseca entre a história da Terra a história das mídias, bem como a relação entre os processos naturais e as tecnologias midiáticas, que vai da extração de minerais ao descarte do lixo eletrônico, passando pela energia utilizada para o funcionamento dessas tecnologias, ver Jussi Parikka (2015).
} 
Maffesoli que aborda a passagem de um processo de développement (desenvolvimento) em favor do enveloppement (envelopamento, pensado no sentido daquilo que envolve, cerca, protege) (HOUDAYER, 2014). De fato, para Maffesoli, esse enveloppement restaura o ser em sua completude, satisfazendo todos os seus sentidos, exprimindo e imprimido uma razão sensível em detrimento de um racionalismo (MAFFESOLI, 2017b).

Houdayer também atenta para o fato de que, mesmo vivenciando todas as práticas ecosóficas pós-modernas, “o homem não renunciou a dimensão tecnológica da sua existência", de sorte que o digital demonstra "um verdadeiro entusiasmo com um estilo de vida que exige a exploração de recursos naturais e o consumo significativo de energia" (HOUDAYER, 2014, p. 89, tradução nossa). Assim sendo, ao refletirmos sobre a nossa relação com a natureza na era do digital é preciso termos em mente que, como nos lembra Edgar Morin, há na natureza das coisas uma dimensão de ordem e desordem que não deve e nem pode ser eliminada. Essa dimensão é ilustrada por Houdayer também com base na ideia de "harmonização dos contrários", coüncidentia oppositorum, de Gilbert Durand.

Esses paradoxos não são algo exterior ao pensamento pós-moderno, mas inerentes a ele. Isso porque, o desejo de coerência é um desejo moderno. O destino da tecnologia está, portanto, nessas acomodações e conexões entre seres humanos e não humanos, nas quais a matéria tecnológica e a matéria natural agem uma sobre a outra. Por isso não podemos entender a nossa relação com os aparatos tecnológicos de maneira utilitária, mas relacional, isto é, por meio da interação entre tecnologia, ambiente e sociedade (SILVA, 2016).

Assim, se como observa Houdayer, o homem, mesmo diante do atual cenário ambiental, não renunciou a sua dimensão tecnológica, ele não o faz porque a técnica é parte constitutiva não somente da vida social, mas da própria concepção de humanidade (LEROI-GOURHAN, 1964). Em relação às tecnologias digitais em rede, elas engendram uma nova forma de estar-com, articulando novas materialidades e novos imaginários, estando cada vez mais integradas ao território, visto como uma fonte de exploração, mas também como um espaço de conexões e reconexões.

É nesse contexto que se insere a ecosofia de Maffesoli, bem como a sua concepção apocalíptica, que compreende não apenas o sentido escatológico do termo, 
mas, fundamentalmente, o seu sentido etimológico, emprestado do latim apocalypsis, isto

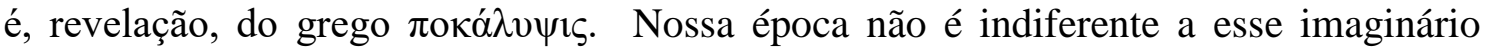
apocalíptico. Vivemos, portanto, o tempo das revelações, desvendamentos e finitudes. Mas, como Maffesoli diz com bastante frequência, o fim de um mundo não é o fim do mundo e a conclusão de uma era também significa o surgimento de uma nova, por isso a ideia de apocalipse como a "revelação das coisas" (MAFFESOLI, 2009, p. 16).

\section{Considerações finais}

Este artigo teve como objetivo apresentar os argumentos sociológicos e filosóficos sobre os quais se fundamenta a noção de ecosofia desenvolvida pelo sociólogo francês Michel Maffesoli. Por conseguinte, buscou-se compreender as implicações tecnocomunicacionais dessa noção. Para tanto, o artigo foi dividido em três eixos de compreensão, quais sejam, a leitura acerca das origens e desenvolvimento do pensamento ecosófico, a concepção maffesoliana de ecosofia e, por fim, os efeitos dessa concepção na compreensão do papel da tecnologia e da comunicação na sociedade atual.

Observou-se que, para Maffesoli, ao contrário da modernidade, sempre orientada em direção ao futuro, a pós-modernidade está enraizada no presente, ou seja, em uma percepção presenteísta do tempo. Nesse sentido, a pós-modernidade seria marcada pelo retorno de esquemas de pensamento holísticos e pela permanência de um "politeísmo de valores", no sentido weberiano do termo, apreensíveis somente por meio de um pensamento pluriforme e dentro da perspectiva de um mundo saturado, devastado social e ambientalmente. Isso indica que, diante dos escombros da modernidade, Maffesoli busca enfatizar o surgimento de pequenos indícios, brechas ou resíduos que podem ser observados, dentro de uma abordagem ecosófica, nos movimentos de valorização da comida orgânica, de defesa da fauna, da flora, na relação com o território urbano ou rural e no surgimento de um novo espírito comunitário. Conforme argumenta o sociólogo: "Existe na experiência cotidiana do espaço vivido uma forma de ligação, de ajustamento ao outro do grupo e a esse ‘outro' que é a natureza.” (MAFFESOLI, 2010, p. 55, tradução nossa).

Observou-se, ainda, que Maffesoli desenvolve a sua noção de ecosofia com base em um pensamento holístico e relacional. Assim sendo, o que está em jogo para 
Maffesoli não é somente o todo social e natural, mas também a correspondência entre os elementos que compõem esse todo, ou seja, as entidades humanas e não-humanas, vivas e não-vivas, visíveis e invisíveis, orgânicas e inorgânicas. A palavra ecosofia é utilizada por Maffesoli com o claro objetivo de se distinguir da ideia de ecologia, cada vez mais inclinada a uma ecologia política e mesmo a partidos políticos. A ecosofia maffesoliana é, pois, da ordem da cultura, ela caracteriza uma ambiência epocal, o ressurgimento da atenção à nossa natureza comum. Assim, para o sociólogo, enquanto a ecologia fala do respeito do homem pela natureza, a ecosofia fala do nosso pertencimento à natureza (MAFFESOLI, 2017b).

Destaca-se, por fim, que esse laço relacional entre humanidade e natureza, sendo essa última pensada no sentido da Terra, onde seres e coisas coexistem e coabitam, segue na obra de Maffesoli uma abordagem heideggeriana de questionamento acerca dos processos de exploração e objetivação da natureza por meio da ciência e da técnica moderna (HEIDEGGER, 2007). Todavia, ao mesmo tempo em que reconhece o papel da tecnologia no atual colapso ambiental, Maffesoli destaca a influência das redes digitais naquilo que ele define como "reencantamento do mundo". Com isso, surge o grande paradoxo não somente do pensamento ecosófico maffesoliano, mas dos próprios movimentos e práticas ecosóficas descritas pelo sociólogo. Isso significa que, ao mesmo tempo em que engendram novas formas de mobilização e participação socioambiental, as tecnologias digitais e em rede corroboram para devastação do planeta. Eis, pois, uma das mais férteis imagens do "trágico pós-moderno", isto é, de uma época que, ao conhecer a finitude do tempo presente, busca acomodar-se a esse tempo.

\section{Referências}

CRUTZEN, P. J. The “Anthropocene”. In: EHLERS, E.; KRAFFT, T. (Org.). . Earth System Science in the Anthropocene. Berlin/Heidelberg: Springer-Verlag, 2006. p. $13-18$.

GOODPASTER, K. On Being Morally Considerable. Journal of Philosophy, n. no 75, p. $308-325,1978$.

GUATTARI, F. Les trois écologies. Paris: Galilée, 2008.

GUATTARI, F. Qu'est-ce que l'écosophie? Paris: Éditions Lignes, 2013. 
HEIDEGGER, M. A questão da técnica. Scientiae Studia, v. 5, n. 3, p. 375-398, 2007.

HOUDAYER, H. Méditer notre relation à la nature aux côtés de Gilbert Durand : les structures anthropologiques de l'imaginaire. Sociétés, v. 123, n. 1, p. 83-90, 2014.

LEROI-GOURHAN, A. Le geste et la parole: technique et langage. Paris: Editions Albin Michel, 1964.

MAFFESOLI, M. Apocalypse. Paris: CNRS éditions, 2009.

. Après la modernité? La logique de la domination ; La violence totalitaire ; La conquête du présent. Paris: CNRS éditions, 2008. (CNRS Compendium).

2 jan. 2017a.

Ecosofia: sabedoria da Casa Comum. Revista Famecos, v. 24, n. 1, p. 24007, Écosophie: une écologie pour notre temps. Paris: Les éditions du Cerf, $2017 b$.

La connaissance ordinaire: précis de sociologie compréhensive. Paris: Klincksieck, 2007. $11,2015$. «La question de la technique » de Martin Heidegger. Sociétés, v. 129, n. 3, p. . L’ordre des choses: penser la postmodernité. Paris: CNRS éditions, 2014. . Matrimonium. Paris: CNRS éditions, 2010. . Tribalisme postmoderne. Sociétés, v. 112, n. 2, p. 7-16, 2011.

; FISCHER, H. La postmodernité à l'heure du numérique: regards croisés sur notre époque. Paris: Éditions François Bourin, 2016.

NÆSS, A. Ecology, Community and Lifestyle: Outline of an Ecosophy. Cambridge: Cambridge Univ. Press, 1998.

PARIKKA, J. A geology of media. Minneapolis ; London: University of Minnesota Press, 2015.

SCHÉRER, R. L'écosophie de Charles Fourier: deux textes inédits. Paris: Anthropos, 2001.

SILVA, D. K. M. DA. Mouvements-Réseau : technique, environnement et socialités à l'époque de l'Anthropocène. 2016. Université Sorbonne Paris Cité, Paris, 2016. 
SIMONDON, G. Sur la technique (1953-1983). Paris: Presses universitaires de France, 2014.

STENGERS, I.; PIGNARRE, P. La sorcellerie capitaliste: pratiques de désenvoûtement. Paris: Découverte, 2005.

TACUSSEL, P. Charles Fourier, le jeu des passions: Actualité d'une pensée utopique. Paris: Desclée de Brouwer, 2000.

TACUSSEL, P. L'imaginaire radical: les mondes possibles et l'esprit utopique selon Charles Fourier. Dijon: Presses du réel, 2007. 